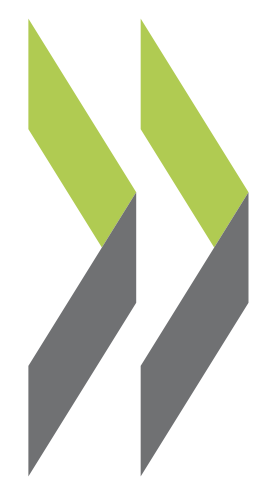

PEB Exchange, Programme on Educational Building 2005/15

\title{
Planning, Designing and Managing Higher Education Institutions
}

\section{William A. Daigneau, Mark S. Valenti,} Sylvana Ricciarini, Stephen O. Bender, Nicole Alleyne, Michael Di Grappa, Josep M. Duart,

Francisco Lupiáñez, Miguel Angel Ehrenzweig Sanchez 


\section{PLANNING, DESIGNING AND MANAGING HIGHER EDUCATION INSTITUTIONS}

Planners, architects and managers seek innovative ways to make efficient use of the resources invested in planning campuses, designing, building and renovating facilities, as well as running universities. New ways to plan, design and manage infrastructure must serve the educational process and improve the quality of the learning environment. Campus space should be flexible and allow for changes in our understanding about how people learn. The planning process needs to honour the institution's history and culture and include input from all the people who will use that space: not only must the needs of students, teachers and staff be fulfilled, but members of the communities in which the space is situated must also be included in the projects as potential users. Sustainability is another growing concern for those involved in planning and managing infrastructure; an increased interest in facilities that respect the environment has already led to the promotion of specific design practices and methods for assessing building performance and meeting sustainability goals.

The OECD Programme on Educational Building, together with the Association of Higher Education Facilities Officers (APPA) and the OECD Programme on Institutional Management in Higher Education, organised an international conference on the planning, design and management of facilities for higher education institutions on 24-27 April 2005.

The purpose of the OECD/APPA conference was to discuss new ideas about campus architecture and to examine important trends and issues that could influence the planning, design and management of higher education institutions. The event concentrated on innovative institutions that respond to current needs in various countries and attempted to define some of the basic concepts that will affect future learning environments.

Much effort has gone into planning new spaces on many campuses over the past years; many lessons have been learned and numerous models which can influence the next generation of buildings are already emerging. The conference endeavoured to identify the various types of tools available for improving higher education facilities and to examine in detail those that seem the most promising.

Developed below is a selection of the ideas and case studies presented at the conference on "Planning, Designing and Managing Higher Education Institutions", in San José, California (United States):

- Megatrends and myths which influence facilities management practices.

- The technology-enabled learning space.

- Natural hazard risk mitigation.

- The modernisation of Montreal's Concordia University.

- An analysis of decision-making in integrating information and communications technology in Spanish universities.

- A network of library and information services units created by Mexico's Veracruz University.

\section{Megatrends and Myths: Facilities Management Practices in Higher Education}

Higher education is going through a period of unprecedented change. What do the changes portend for the future? For people involved in planning and managing facilities for higher education, this question is particularly germane. The choices a facilities professional makes today often affect a higher education institution for decades to come. And that in turn affects the capacity of higher education to successfully fulfil its mission of education and research.
Any decision to create space needed to support educational or research processes can and should be viewed as an investment decision. When we create space, are we not investing current and future resources into a facilities asset with the expectation that this investment will result in future benefits? If so, then any investment should be evaluated by its future returns, measured by the length of time the asset is productive and the benefits it generates. If we extend this logic to every campus facility, we could theoretically rank each investment decision in terms of its return on investment. In a purely economic sense, success for a university means maximising its returns per dollar invested. 
Today we can identify a number "megatrends" 1 which help us analyse and measure the major forces that shape the future. These megatrends are important to understand since they fundamentally influence returns on investment.

If in fact the space in a university is configured at any point in time to support the functions and processes employed by that institution, then one can say that the usefulness of that space will be altered if the functions and processes for which it was originally designed change. If the space can no longer support the new function, the return from that space drops to zero, and either reinvestment to alter the space is required, the space is abandoned or a different function is assigned to the space if it can be successfully accommodated. Only through one of these three choices can return on investment be maintained or increased, otherwise a negative return on investment will occur. So the following question must be asked: What megatrends will influence the functions and processes of higher education in the future?

Megatrends can be grouped into five categories related to changes in society, economics, technology, government and the environment. While the following summary of megatrends is primarily focused on higher education in the United States, what evolves here can likely be extrapolated to other countries and their higher educations systems.

\section{- Megatrend 1 - Society: Changing student demographics}

For many decades, higher education served a fairly homogeneous student population, but that has changed dramatically and continues to do so. The mix of students today includes differences in gender, nationality, race, economic class, age, employment and family. In response to this change, educational systems are increasingly customised to address the larger variance in educational needs and goals. As educational processes and functions evolve, how will older space support these changes and what will be future facility requirements, both in terms of type and location?

\section{- Megatrend 2 - Economics: Access and efficiency}

Since 1980, the growth of tuition costs in the United States has outpaced inflation by $179 \%$. It is certain that such an increase cannot be sustained without eventually closing the door to large groups of potential students. The bottom line is that economic and societal development require a well-educated workforce. Given a choice between putting higher education out of the financial reach of large portions of the population and finding more efficient ways to deliver higher education, the latter

1. This term was first coined by John Naisbitt in his 1982 bestseller Megatrends. is likely to prevail. The pressure to control these costs will undoubtedly drive changes in educational processes and thus in the design and demand for different types of facilities.

\section{- Megatrend 3 - Technology: Information technology and cost}

Technology in higher education systems has two dimensions. The first is information technology. It has been postulated that information technology has made possible a shift from the traditional "instructional" paradigm to a "learning" paradigm, where face-to-face time with a faculty member would be devoted to laboratory or demonstration style sessions and not to lecture type instruction. This educational process and others like it would not only make classrooms and lecture halls obsolete, but also could significantly improve efficiency and reduce the cost of instruction.

The other dimension of technology is cost, primarily as it pertains to the research mission of higher education. Today's research facilities are some of the most costly to build, equip and operate. As the cost of supporting research increases, more and more research may be concentrated at fewer and fewer institutions, those that possess the critical mass to continue to support this investment. Again such concentration will reshape the missions of higher education institutions and thus affect both existing and future space requirements.

\section{- Megatrend 4 - Government: Accountability}

With a stable society and economic development at stake, government has increasingly inserted itself into the debate about higher education. Will greater activism by government in the management of higher education lead to more mandates on the "what, where and how"? If government more tightly controls resource allocation and programmes decisions, both in education and research, will there also be greater controls on building construction?

\section{- Megatrend 5 - Environment: Reuse, recycle, reduce}

Never has concern over environmental protection been greater than it is now. Issues about the environment include indoor air quality, day lighting and energy efficiency. As energy prices again begin to rise, there will be even greater pressure to revise buildings (reuse) or adopt new design standards (recycle), and even more importantly to actually improve utilisation (reduce). What impact will environmental concerns have on future facility decisions?

While no one knows exactly what the future holds, the above-mentioned megatrends have the capacity to dramatically reshape higher education, and to do so in a relatively 
short period of time. And if such changes do happen, there will also be dramatic changes in how educational facilities are planned, designed and managed.

In addition to asking how, and how quickly, the megatrends will affect decisions on what and how much space to build, some facilities management practices and beliefs should be seriously re-examined. These are the current "myths" of higher education facilities management.

\section{- Myth 1: Build for the long haul}

Many facilities managers believe they should construct buildings to last for 50 or even 100 years. But space built today to satisfy a specific need or technology may not provide tomorrow's expected returns if higher education goes through a major paradigm shift.

\section{- Myth 2: Build flexibility into the design}

The question is: "flexibility for what?" Building so-called flexible buildings assumes one knows enough about the future to plan for it in the design. Many such investments prove worthless.

\section{- Myth 3: Form follows function}

Today almost every building constructed for higher education in the United States is custom built. Unfortunately, as programme needs change and the building does not, form begins to "influence", or worse "dictate", function. During any period of change, all design standards based on past practice need to be openly challenged.

\section{- Myth 4: Deferred maintenance is bad}

Some existing facilities are not likely to generate a future return on their initial investment. These buildings represent a sunk cost, and further investment in them should be curtailed. We need to understand that not all deferred maintenance is bad, only that which is unplanned.

\section{- Myth 5: Facilities attract students}

Facilities are not a primary motivator in a student's choice of a higher education institution. Most students are motivated by factors other than how the campus looks: the institution's reputation, the programmes it offers, whether they can afford it, what others think (for example, parents or friends), and its location. Money spent beyond that necessary to support good education or research is simply wasted.

The people who plan, design and manage higher education facilities are in a critical position to prepare for change and ensure success, and there are a few things that will help them fulfil that responsibility. First, facilities management officers must understand the impact of their decisions in terms of both today's and tomorrow's context. Second, they need to treat the various campus buildings as a portfolio of investments and should maximise the value of the total portfolio, not the individual investments alone. Third, they must make a proactive effort to develop facilities strategies that will better position their institutions to deal with changing paradigms and economic conditions. And lastly, they must shed their own narrow view that they are just the stewards of facilities and must better understand the complete functioning of higher education: its economics, its processes and its purpose. Only then will they be able to help higher education meet its worthy mission of enhancing the knowledge of humankind.

Article by:

William A. Daigneau

Vice President and Chief Facilities Officer

University of Texas, MD Anderson Cancer Center

Houston, Texas, United States

Fax: 17137451753

E-mail: daigneau@mdanderson.org

\section{The Technology-Enabled Learning Space}

The classroom, once the domain of the professional lecturer, is fast becoming a multimedia-intensive, highly collaborative facility used to produce and consume media-rich materials. Today's students are adept at manipulating digital media of all types, and it is not an unreasonable leap to imagine students extracting the chunks of audio, video and graphics that are most relevant to their interests or needs in order to develop an understanding of the requisite course concepts. It is another short hop to imagine those chunks being shared among members of an informal work group, or learning community, formed to help participants navigate the course together. In the classroom, it is easy to imagine students retrieving their work for display and discussion with fellow students and the instructor. In fact, it is useful to think of both teacher and student in this setting as "prosumers". This is a made-up word, but it can begin to shape our perceptions of the activities that occur in the classroom and subsequently of the criteria that are used to plan, programme and design new, flexible, technologyenabled learning spaces.

\section{AV/IT convergence}

Underlying the development of the technology-enabled learning space is the convergence of audiovisual (AV) and information technologies (IT). This is an emerging trend with dramatic long-term consequences for colleges and universities and is a key reason why many students have already moved beyond the basic lecture-presentation classroom model. 
The audiovisual wave, which began in earnest with the development of low-cost liquid crystal display projectors in the mid-1990s, continues to play out. Unlike telecommunications, personal computing and data networking, the audiovisual component of the campus has not yet achieved respect as a mission-critical technology. That is changing rapidly, however, because in the classroom of the future, audiovisual tools coupled with reliable, high-performance networking will be essential. New developments in audio, video, digital broadcasting and systems control, along with continuing advances in optical and wireless networking, point to a media-rich future.

From a systems perspective, low-cost digital signal processing technology has revolutionised the design of audiovisual systems, from recording and post-production to presentation and display. Today, sophisticated multipurpose rooms feature powerful, flexible systems that support a broad variety of applications, from basic PowerPoint ${ }^{\mathrm{TM}}$ to sophisticated multimedia conferencing such as Access Grid ${ }^{\mathrm{TM}}$.

Another development emerging from the convergence of $\mathrm{AV}$ and IT is a new set of control and systems-management tools. Advantages include the ability to create a universal user-control interface for audiovisual systems across the institution and a significantly improved ability to manage audiovisual assets. A universal user-control interface lowers training and technical support costs and enhances usability of the audiovisual tools. The "Dashboard Project", an audiovisual industry collaboration between institutional end users and systems designers, is striving to create a set of universal user interface design principles. System usage patterns, individual device status, user access and remote troubleshooting are examples of IT functions incorporated in the audiovisual environment. New organisational and financial models, such as combination AV/IT help desks and life-cycle funding analyses, are helping manage and maintain a complex technology base.

\section{Perils and plans}

The technology-enabled learning space and the convergence of AV and IT are affecting every facet of campus facilities and systems design, engineering, implementation, and operations. New technologies are enabling new applications as quickly as we can imagine them. The challenge is to anticipate the impact of these new technologies and understand how related areas such as staffing, organisation, evaluation metrics and operating costs are affected. This analysis can then serve as the basis for an informed design of systems and related infrastructure. The design of new campus educational and research facilities - including not only classrooms and laboratories but also student union facilities, recreational centres and residence halls - has become extremely audiovisual-intensive, reflecting our culture's reliance on visual communications and entertainment. It is not unusual for the audiovisual technology budget to be USD 2 to 3 million for one academic building; USD 1 million is quite ordinary today. To put that in perspective, outfitting the data network for the same building may cost USD 500000 and telecommunications about USD 400 to 500 per station. Imagining a successful long-term technology implementation without a cohesive, co-ordinated approach to data, voice and visual communications is nearly impossible.

The problem today is the way new campus buildings are planned and financed. Wherever the project originates - whether with the state board of regents or the college/university facilities group - most institutions do not adequately factor in the cost of a converged technology solution. Historically, data and telecommunications cabling is assumed to be part of the building (Group 1 costs), whereas audiovisual technologies are included as part of the furniture, fixtures and equipment budget (Group 2 costs). In this model, the furniture, fixtures and equipment budget often becomes the "contingency fund".

This model presents numerous perils:

- Functionality and/or quality are pushed out of the solution.

- The classroom systems in the new building bear no resemblance to those in the building next door, which may have been completed only two years earlier.

- Some classrooms are fitted out, whereas others await equipment funding for two or three years.

- Instructors struggle with inconsistent user controls.

- Technical support personnel struggle with inconsistent solutions.

- The registrar struggles with classroom scheduling and with demands for "rooms that work".

Enlightened institutions are beginning to recognise that without a cohesive technology plan and budget, campus facilities will not be effective teaching, learning or research environments. A cohesive plan includes three steps:

1.Organise. The first step is to organise, under one roof, the responsibility for information technologies, communications technologies and instructional technologies. For example, the classroom-support personnel and the desktop-support staff should be put in the same room and held to the same performance standards; eventually, the two groups will be the same. Data, telecom and media distribution technologies should be co-located; eventually, they will run on the same 
equipment. The facilities department should become a strategic partner of sorts to implement the building of the future; eventually, its buildings will run, literally, on the institutional network. (Advances in building automation and other "typical" facilities systems such as power management and heating, ventilation and airconditioning monitoring/control now require network infrastructure and bandwidth.)

2. Participate. Those responsible for information technology should insist on participating in the planning, design and construction table. A project manager should be assigned with responsibility for the technology component of any project. Most campus facilities project managers will gladly accept the expertise and assistance. Most design consultants will likewise welcome the expertise and assistance. The opportunity to build consistency across multiple projects must be created; it will not just happen.

3. Interface. A standard user interface must be established for classroom technologies. A consistent user interface enhances usability, manageability, serviceability and scalability of audiovisual systems. It almost certainly improves return on investment, although no comprehensive research seems to have been performed yet in the higher education marketplace.

Students adapt readily and quickly to new technologies, and they increasingly vote with their feet. The campus technology environment plays a key decision-making role when students are selecting an institution. For some, it means, "What's available in my dorm room?" For others, it is a matter of after-hours access to online learning. The contemporary college or university must be adept at teaching students both on and off campus, providing opportunities for learning on the students' terms. This translates into a flexible learning environment that slips easily between real and virtual learning spaces. Two keys to developing that kind of environment are a flexible, technology-enabled classroom and a comprehensive AV/IT infrastructure. The tools and expertise are in the marketplace. Creating the future requires simply commitment and clear vision.

\section{Article by:}

Mark S. Valenti, President

The Sextant Group, Inc.

Pittsburgh, Pennsylvania, United States

Fax: 14123238538

E-mail: mvalenti@thesextantgroup.com

The Sextant Group is a full-service consulting firm specialising in planning and design of learning, communications, and entertainment facilities and systems.

\section{Natural Hazard Risk Mitigation in Higher Education Infrastructure}

Addressing natural hazards risk within the diverse organisational structures of higher education institutions is a complex task. This also represents a new challenge to the sector's facility planning and management. Hence, those involved in the financing, ownership, management, design, construction and maintenance of higher education institutions must work together to provide a safe, high quality learning environment that is resistant to the impacts of natural hazards.

Natural hazards not only affect campus infrastructure including laboratories and research centres but they can also result in the temporary or permanent closure of the university. This can threaten the continuity of academic programmes disrupting staff and students and in some cases lead to a decrease in university enrolment. ${ }^{1}$

Figure 1

Building damage in educational facilities after the 1999 Quindio earthquake in Colombia

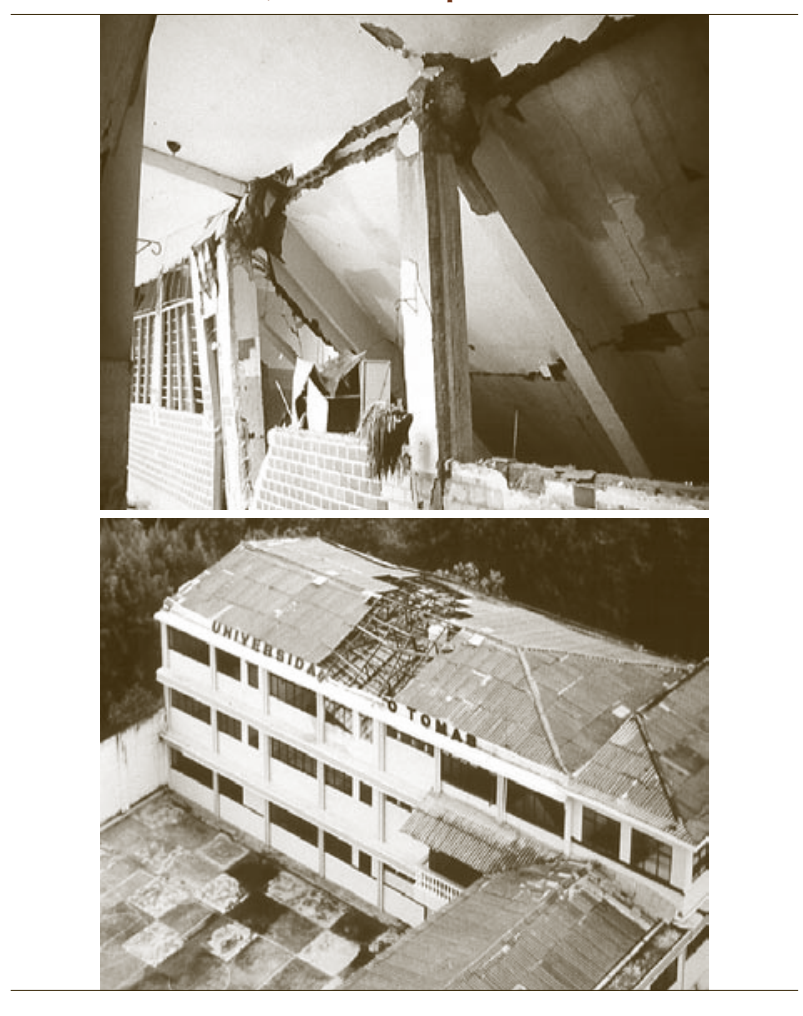

Source: Omar D. Cardona,

Universidad Nacional de Colombia, Manizales

1. Ricciarini, Sylvana (2005), "Guidance Material for the Design and Implementation of Mitigation to Natural Hazards Plans", working document, executive guidance, The Disaster Reduction of University Campuses in the Americas (DRUCA) Program, Office for Sustainable Development and Environment (OSDE) of the Organization of American States (OAS), July. 
In recent years, natural hazards such as earthquakes and hurricanes have revealed the vulnerability of several higher education facilities in the Americas, leading to loss of life and property damage (Figure 1). In 2004 approximately $95 \%$ of the buildings at the University of West Florida were damaged as a result of Hurricane Ivan, although much of that damage was repaired relatively rapidly. ${ }^{2}$

\section{Challenges to risk mitigation in the higher education sector}

Natural hazards risk mitigation in the higher education sector faces a number of challenges. Poor building design, construction and supervision practices, facility location in hazard-prone areas, antiquated building stock, and weak enforcement of building codes are some issues that need to be addressed by natural hazards risk mitigation, as part of a broader strategy for disaster risk management.

A number of factors can impede progress towards successfully integrating risk management into facility planning, design, construction and management in new and existing infrastructure:

- Different organisational, ownership, responsibility and accountability structures.

- Lack of general physical, economic and financial risk management strategies.

- Lack of ownership of risk mitigation strategies.

- Shortage of proactive decision-making.

- Lack of human and financial resources.

\section{Vulnerability reduction in the higher education sector}

Risk and vulnerability reduction is possible even more today considering the advances in technology, engineering and finance that impact on the project cycle of higher education sector infrastructure.

Vulnerability reduction to natural hazards should be considered at all phases of the project cycle, from design to construction, to ensure that regulatory regimes and enforcement mechanisms are implemented (Figure 2). Good design alone does not solve the problem of risk, but it is a crucial step towards reducing vulnerability. It is estimated that mitigation against natural hazards adds less than $10 \%$ to the capital cost of the entire project at the time of initial design and construction. ${ }^{3}$

Reducing vulnerability requires addressing risk factors at the correct phase of the project cycle, in the context of long-term facility planning. To ensure that the infrastructure (both new and existing) is resistant to the impact of natural hazards the following questions should be discussed:

- What is the expected lifetime of the building under construction?

- What are the intended uses of the building? Will it be used as a shelter?

- What hazards are the building exposed to?

- How often and how severe could each hazard occur within the structure's lifetime?

\section{Risk mitigation in new facilities}

Issues to consider in planning, designing and constructing new infrastructure are:

- Natural hazard forces.

- Site planning, i.e. ensuring that structures are not situated in hazard-prone areas and can withstand the impacts of natural hazards, such as wind or ground acceleration.

- Land use planning.

- Application and enforcement of building codes.

- Good construction practices.

- Good governance to ensure the quality and continuity of work.

\section{Risk mitigation for existing facilities}

Often, investment in a structure's external appearance and comfort is preferred to investment in seismic retrofitting, wind resistant roofs or other elements that would lower risk to natural hazards. In addition, the issue of vulnerability reduction and natural hazard mitigation is frequently ignored; many believe that although mitigation is effective, it is not financially viable for smaller, less wealthy institutions. Nevertheless, there is evidence that retrofitting higher education facilities is feasible and can be carried out at an acceptable cost. Such an investment can also be seen in broader terms, as an investment in the higher education sector, its infrastructure, knowledge transfer systems, institutional policy, social mobility and donor-recipient relationships.

\section{Risk transfer}

Given the costs and difficulties involved in lowering natural hazards risk to zero through structural and nonstructural mitigation measures, risk transfer mechanisms

2. University of West Florida, "UWF in Touch: Message from the President", http://uwf.edu/uwfmain/hurricane/assistance.htm.

3. USAID, OAS, ECHO (2001), "School/Shelter Hazard Vulnerability Reduction Resource Page", Caribbean Disaster Mitigation Project (CDMP), April, www.oas.org/cdmp/schools/schlrcsc.htm. 
have been increasingly used in developed countries to absorb losses from property damage. Insurance is therefore a means of transferring potential fiscal losses due to the impact of natural events away from the victims. If a natural hazard should occur at a university, it is important to protect the facilities and maintain their operations. To that end, insurance mechanisms, including the creation of contingency funds to strengthen economic and fiscal resilience, are often part of a comprehensive disaster risk management strategy.

\section{Disaster Reduction of University Campuses in the Americas (DRUCA)}

Reducing risk is an emerging issue for most higher education institutions in the Americas. Platforms that allow information exchange and knowledge transfer processes related to designing and implementing mitigation plans are essential to mainstream risk reduction in the higher education sector. In this context, the Organization of American States (OAS) and its programme for Disaster Reduction of University Campuses in the Americas (DRUCA) aim to provide technical assistance and facilitate knowledge transfer related to natural hazards risk management among institutions in the Western Hemisphere. DRUCA activities include sharing experiences, capacity building and mentoring, as well as establishing an advisory network among colleges and universities in the Americas. ${ }^{4}$

Figure 2

Opportunities to incorporate natural hazards risk mitigation in the project cycle of higher education infrastructure

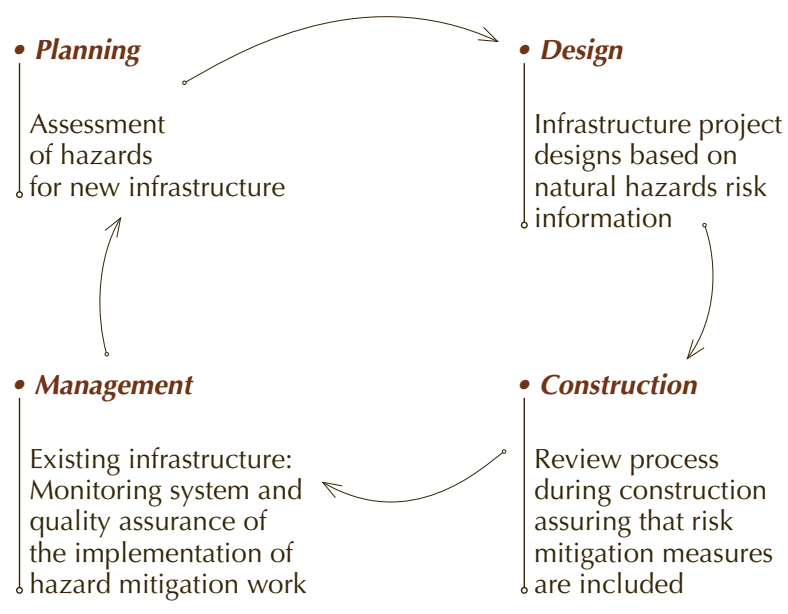

4. Organization of American States (OAS) (2005), Disaster Reduction of University Campuses in the Americas (DRUCA) Web page, www.oas.org/nhp/DRUCA/DRUCA.eng.mht, accessed 8 July 2005.
Each university is ultimately responsible for its own vulnerability reduction to natural hazard events. The DRUCA programme has documented that while universities have varying technical and institutional approaches, priorities and resources to address natural hazards risk management, there is a set of basic components of a risk mitigation programme and a core set of decisions that have to be made by every institution. Far too few vulnerable universities have addressed the risk management issue, but there are universities, professional societies, individual professionals and international programmes such as DRUCA that are prepared to support those that wish to begin the process (Figure 2).

Article by:

Sylvana Ricciarini, Civil Engineer

Fax: 12024583560

E-mail: ricciarini@aol.com

and

Stephen O. Bender,

Division Chief, Natural Hazards

Office for Sustainable Development

and Environment (OSDE)

Organization of American States (OAS)

Washington, DC, United States

E-mail: sbender@oas.org

With the assistance of Nicole Alleyne

Office for Sustainable Development

and Environment (OSDE)

Organization of American States (OAS)

\section{Montreal's Concordia University: Building a Modern Campus}

In 1999, Concordia University - a 25-year-old operation - had reached the boiling point. Enrolment was growing rapidly and would jump by $40 \%$ in six years. A closed movie theatre, a church basement and a secretarial college had become short-term academic space.

This article describes Concordia's physical transformation. It explores how the university's academic plan, the challenge of financing a massive building project, energy and cost efficiency, information technology (IT) and sustainable development played major roles in the transformation.

As John Fitzgerald Kennedy said: "There are risks and costs to a programme of action. But they are far less than the long-range risks and costs of comfortable inaction." At Concordia University, the time had come for a programme of action. 


\section{E-strategies: ICT at Spanish universities}

Over the past ten years, information and communications technology (ICT) has become firmly established in Spanish universities and has indisputably led to radical changes in the internal dynamics of these institutions: changes to the planning and practice of teaching at universities, to university administration and services for students and, significantly, to research and dissemination activities.

As well as enabling universities to modernise their administrative procedures, introduce innovative teaching and learning methods, and facilitate access by new groups of students (especially adults), ICT is also gradually beginning to usher in organisational change. ${ }^{1}$ The introduction of ICT, whether in a university, company or other institution, has an impact not only on the processes and value chain of the institution in question, but on the internal structure of the organisation itself. ${ }^{2}$

The Open University of Catalonia analysed strategic decision-making in integrating ICT into Spanish universities under the framework of the E-strategies project, a qualitative study financed by the Ministry of Education.

The study looks at the decisions implemented by the university executive and at the impact of decisions - planned and unplanned - which led to the introduction and use of ICT in university education. The report attempts to identify the main problems that were encountered in the decision-making process and in the strategies adopted by universities. It analyses them from a horizontal and a vertical perspective:

- Horizontally, looking at decision-making processes and their compatibility with the university's strategic planning and social demand.

- Vertically, focusing principally on the following three areas: investment in technology, organisational change (with particular reference to libraries and academic services), and motivation and incentives for innovation and use of ICT in teaching.

1. Gayle, Dennis John, Bhoendradatt Tewarie and A. Quinton White, Jr. (2003), "Challenges to University Governance Structures, in Governance in the Twenty-First-Century University: Approaches to Effective Leadership and Strategic Management, ASHE Higher Education Report Vol. 30, No. 1, Wiley Periodicals, Inc.

2. Carnoy, Martin (2004), "Las TIC en la enseñanza: posibilidades y retos", in UOC (2004), Lección inaugural del curso académico 2004-2005 de la UOC, Barcelona, www.uoc.edu/inaugural04/dt/ esp/carnoy1004.pdf, accessed 28 October 2004
The figure below illustrates the analysis model.

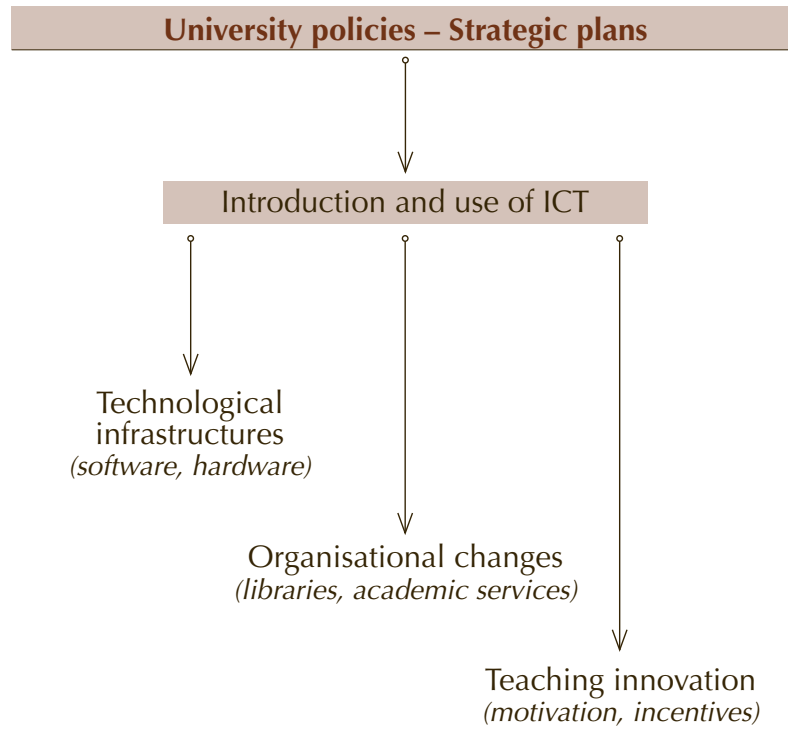

To conduct the horizontal analysis, an institutional analysis model adapted from Stonich's ${ }^{3}$ strategic model was used, based on the features given in the following figure:

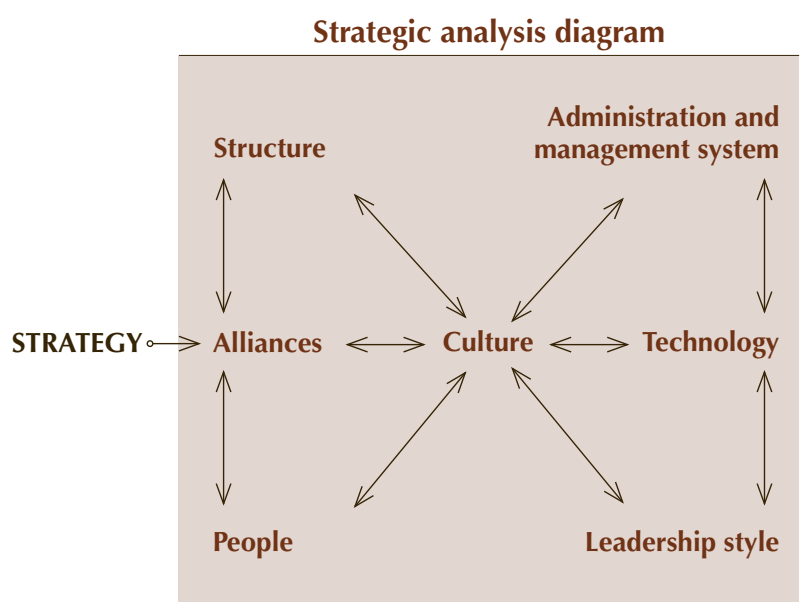

Broadly, it is fair to conclude that ICT was introduced into Spanish universities without strategic planning, being prompted by external demand (the demands of the knowledge society, student demand and the European Higher Education Area). However, today there is a clear trend towards the development of institutional strategic policy and its implementation through specific plans.

3. Stonich, P. J. (1982), "How to Implement Strategy", analysis model adaptation after Carles Esquerré, Editorial Instituto de Empresa, Madrid. 
Obvious rigidities in university structure, particularly as regards regulations on posts and functions, can initially make the process of introducing and using ICT in universities difficult. But university leaders can facilitate change by creatively designing different formulae.

The study identified internal and external alliances. Internal alliances, between administrative staff and faculty, and external alliances, particularly between universities, have formed in order to meet common needs especially for technology services providers.

Under the "People" heading, the salient finding was that new job profiles have developed, some of which are even new to the labour market. Further, specific training and internal promotion proved to be incentives for introducing and using ICT.

The analysis of cultural aspects showed a change towards a more user-oriented culture. Instead of focusing on internal dynamics, the focus is now consistently on the needs of users and society. As a result of ICT use, and the use of corporate Intranets in particular, a new culture of internal communication and access to information has developed.

The administration and management system requires (1) a motivated decision-making group for strategic ICT processes, and (2) a clear policy on introducing technology to support innovation and change. That there is steadily greater access to information is clear. Management views ICT as a governance and decision-making tool.

The horizontality that technology introduces into the normal administrative and teaching process has proved to be one of the determining factors in organisational change, creating a need for dialogue and teamwork between teaching and administrative staff.

As a result of investment over the past decade, Spanish universities now have good technological infrastructure, and the focus is increasingly on accessibility, connectivity and portability. These aspects apply not only to physical infrastructure but to services as well. There is also a clear trend towards standardising virtual learning environments in universities, whether these environments are produced in-house or are outsourced.

Although ICT was first introduced in universities without the necessary planning, the university executive has since played a leadership role. Interestingly, in most Spanish universities the lead has been taken by rectors or vicerectors working in tandem with the university's head of administration. Leadership at intermediate levels by deans or by departmental, administrative and support services directorates has also been highly significant.

For further information on the E-strategies project, visit www.uoc.edu/in3/e-strategias/cat/index.htm/ or www.uoc. edu/web/eng.

Article by:

Josep M. Duart

UNESCO E-Learning Chair Co-ordinator

Universitat Oberta de Catalunya (UOC)

Barcelona, Spain

Fax: 34934175129

E-mail: jduart@uoc.edu

and

Francisco Lupiáñez

UOC UNESCO Chair Support

Fax: 34934175129

E-mail: flupianez@uoc.edu

\section{Libraries and information services units in the State of Veracruz}

Mexico's Veracruz University has created a network of library and information services units (USBI) in modernising its campuses as part of a flexible, integrated education model.

This public university, with campuses in 14 towns across the State of Veracruz and 119 vocational and non-formal education programmes, required new infrastructure to meet the needs of its new academic programmes. Conscious of its responsibility as a public institution in today's knowledge society, Veracruz University made as the central pillar of its 2001-2005 work programme to become an agent for the social transfer of knowledge.

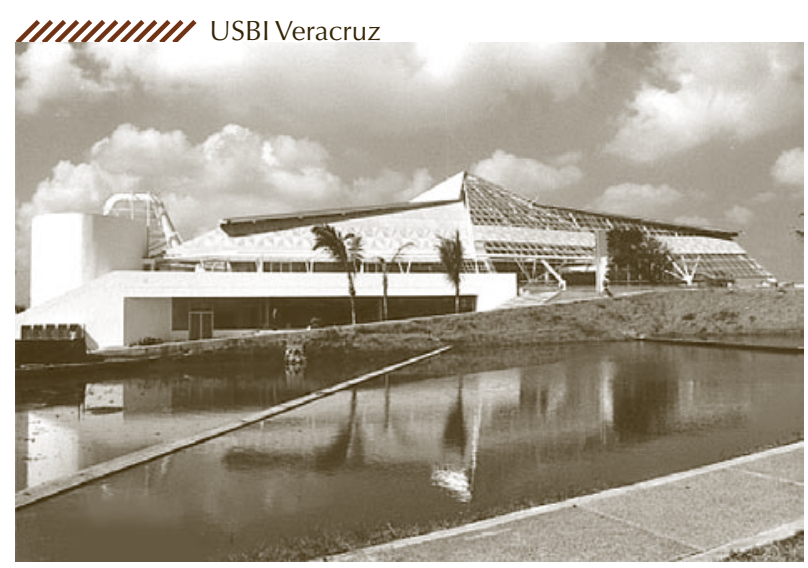


WIIIIIIIIIIII Design for USBI Ixtac

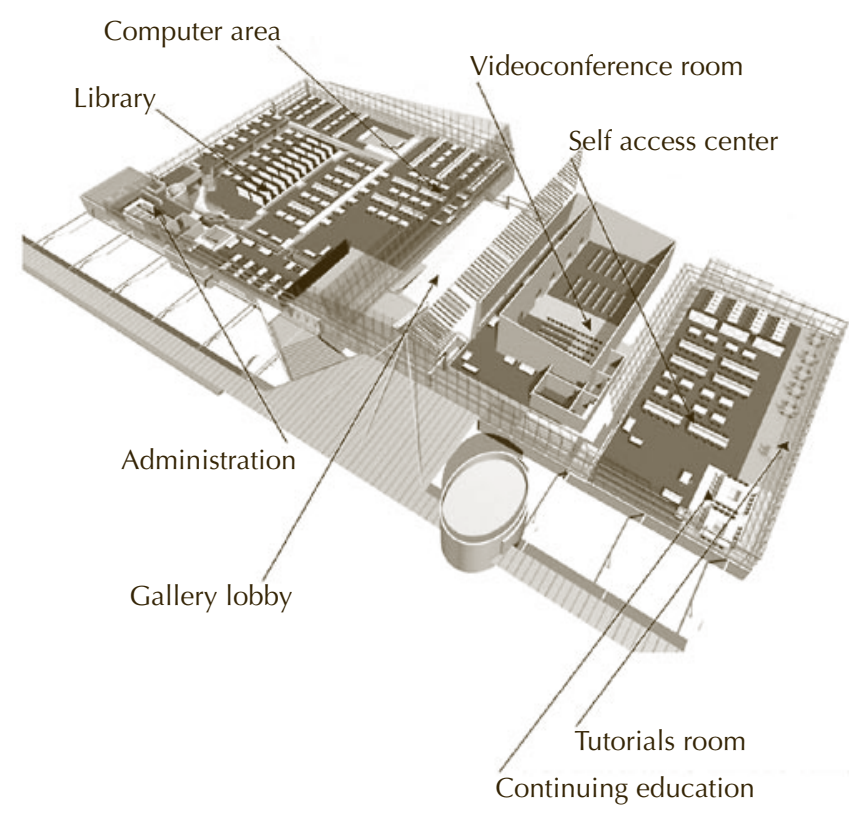

This project reflects international trends in higher education and the recommendations of international organisations. At the 1998 "World Conference on Higher Education" in Paris, UNESCO concluded that the skills required by the knowledge worker are: learning to know, learning to do, learning to be and learning to live together. The OECD for its part defines the workplace competencies required in the knowledge society as follows: the ability to collaborate and work in a team, leadership capabilities, the ability to learn, problem-solving skills, effective communication skills, and technological literacy.

The institution's new flexible, integrated education model is centred on student learning, with information and communications technology (ICT) supporting the work of teachers and students. The principal of the model is to guide the student in self-learning and discovery, avoiding the traditional teacher/classroom system of merely transmitting information. The university's new vocational education programmes include private study, group learning, tutorials and access to multiple information sources.

After analysing various alternatives, a building was designed to respond to the modernisation of the university's academic programmes through the use of ICT while conserving the university's traditional libraries. The result is the library and information services units, which are large multi-purpose educational spaces with flexible equipment, large storage capacity, and space for computer, video and audio equipment.

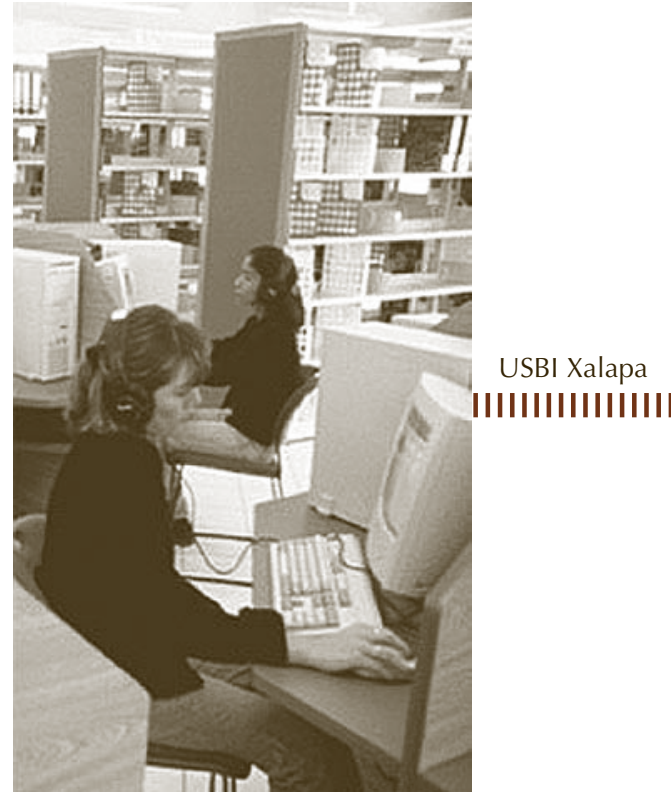

The USBI facilities are adapted to the flexible, integrated education model which caters to lifelong, self-learning common to the 16 technical career options offered by the university. The infrastructure supports activities to learn reading, writing, problem-solving, basic computing, foreign languages and development skills. The units include private study facilities for self-learning activities (e.g. studying foreign languages) and connect students to information media through the use of technology, with teacher guidance.

To date, Veracruz University has built and equipped five of these buildings, which serve $83 \%$ of the total enrolment of 60000 students. Construction has begun on two new library and information services units in the OrizabaCordoba region.

Building programmes undertaken by Veracruz University also seek to develop and improve green areas by creating bodies of water and planting species typical of each region, thus promoting a culture of ecology and improving the quality of the public campuses.

Article by:

Miguel Angel Ehrenzweig Sanchez

Director of Projects

Buildings and Maintenance

Universidad Veracruzana

Mexico

Fax: 2288177902

E-mail:mzweig@uv.mx 